\title{
EFFICACY OF AQUEOUS GARLIC EXTRACT ON GROWTH, AFLATOXIN B1 PRODUCTION, AND CYTO- MORPHOLOGICAL ABERRATIONS OF ASPERGILLUS FLAVUS, CAUSING HUMAN OPHTHALMIC INFECTION: TOPICAL TREATMENT OF A. FLAVUS KERATITIS
}

\author{
Ahmed A. Ismaiel $^{1 *}$, Gamal H. Rabie ${ }^{1}$, Saied E.M. Kenawey ${ }^{2}$, Marwa A. Abd EL-Aal ${ }^{1}$ \\ ${ }^{1}$ Department of Botany and Microbiology, Faculty of Science, Zagazig University, Zagazig, Egypt; ${ }^{2}$ Department of \\ Ophthalmology, Faculty of Medicine, Zagazig University, Zagazig, Egypt.
}

Submitted: October 31, 2011; Returned to authors for corrections: January 12, 2012; Approved: June 07, 2012.

\begin{abstract}
By using agar well diffusion assay, antifungal activity of aqueous extract prepared from Egyptian garlic (Allium sativum L.) was evaluated in vitro against two strains of Aspergillus flavus (OC1 and $\mathrm{OC} 10$ ) causing human ocular infection. The recorded minimum inhibitory concentration (MIC) for growth inhibition of both strains was $3.60 \mathrm{mg} / \mathrm{ml}$. Aqueous garlic extract (AGE) was used in successive in vivo tests as an attempt to cure rabbit's fungal keratitis caused by A. flavus OC1. Findings showed that diluted preparation of AGE was effective topical antifungal agent and succeeded to cure severe $A$. flavus keratitis in a time course less than 10 days without any observable side effects. Microscopic examination showed that AGE induced deleterious cyto-morphological aberrations in A. flavus target cells. AGE applied to Czapek's broth via contact method was more effective on growth, spores and aflatoxin B1 production than AGE applied to the same broth at the same concentration via fumigation method.
\end{abstract}

Key words: Aspergillus flavus; Garlic; Antifungal; Keratitis; Microscopic examination; Aflatoxin B1

\section{INTRODUCTION}

Aspergillus flavus is an important cause of invasive aspergillosis (14) and has emerged as predominant pathogens in patients' sinusitis and fungal keratitis (12). Various specific antifungal agents have used in many trials to cure fungal keratitis with varying degrees of success. However, these antifungals are expensive and not usually available in developing countries (8). A. flavus produces a group of structurally related difuranocoumarin derivatives known as aflatoxins. Aflatoxin B1 is the most extremely toxic, mutagenic and carcinogenic type $(6,25)$. Inactivation of aflatoxins by physical (treatment with heat, UV light or ionizing radiation) or chemical methods (addition of chlorinating, oxidizing or hydrolytic agents) bears many drawbacks (20).

Garlic has been used in folk medicine due to its natural antimicrobial activity in various trials $(4,7,24,27)$. Garlic is often combined with herb mullein in oil products designed to reduce pain of middle ear infection (26). Arabic herbalists used garlic to treat abdominal pain, infantile colic, diarrhea,

*Corresponding Author. Mailing address: Department of Botany and Microbiology, Faculty of Science, Zagazig University, Zagazig, Egypt.; E-mail: microbiologist_80@yahoo.com 
diabetes, eye infections, snake bites, dandruff and tuberculosis (1). Its broad spectrum of activity has been attributed to phytotherapeutic sulfur compounds including allicin and thiosulfinates, which are formed by crushing-induced metabolic action of enzyme alliin layase / alliinase on the odorless amino acid alliin (5). In a previous study, 17 active components of Egyptian garlic were identified and responsible for antifungal activity (10). This study evaluates in vitro antifungal potential of AGE against two clinical strains of $A$. flavus. The particular possibility to use AGE in vivo as effective topical antifungal agent against $A$. flavus keratitis has not been previously reported. Microscopic examination was used to study the cyto-morphological aberrations induced by AGE. Efficacy of AGE in inhibition of aflatoxin B1 production was also investigated in this article.

\section{MATERIALS AND METHODS}

\section{Garlic bulbs and aqueous garlic extract (AGE) preparation}

Fresh garlic (Allium sativum L.) bulbs were purchased from local markets in Zagazig town, Egypt. The cloves were peeled and washed several times. A known weight (255 g) was blended in $900 \mathrm{ml}$ of distilled water, and homogenized in a domestic juicer (Braun Combimax 700 Vital, Germany) for 3 min at average speed to extract the juice which was then centrifuged at $3000 \mathrm{rpm}$ for $10 \mathrm{~min}$. The precipitated material was weighed and supernatant was filtered through Whatman no. 1 filter paper and resulting filtrate was filter sterilized by passing through a $0.45 \mu \mathrm{m}$ cellulose nitrate membrane filter to give crude aqueous extract of $71 \mathrm{mg}$ of garlic/ml. AGE was used immediately or stored at $4{ }^{\circ} \mathrm{C}$ until used.

\section{Fungal strains}

A. flavus OC1 and A. flavus OC10, clinical aflatoxigenic strains have been isolated from human cases diagnosed to have resistant corneal ulcer and corneal abscess, respectively. Isolates were identified to the species level based on macroscopic and microscopic morphology on Czapek's agar according to Moubasher (17).

\section{Bioassays}

In vitro tests: Agar well diffusion method (10) was used for determination of antifungal activity of AGE. In brief, $25 \mathrm{ml}$ of Czapek's agar was inoculated separately in a Petri-dish with $0.2 \mathrm{ml}$ of A. flavus $\mathrm{OC} 1$ and OC10 conidial spore suspension $\left(10^{6}\right.$ spores/ $\left.\mathrm{ml}\right)$ from $168 \mathrm{~h}$ old cultures. Wells $(10 \mathrm{~mm}$, diameter) were aseptically bored into culture medium and $70 \mu \mathrm{l}$ of AGE was added to each well. Effectiveness of AGE was tested at different concentrations (Table 1). The plates, after staying at $4{ }^{\circ} \mathrm{C}$ for $6 \mathrm{~h}$ were incubated for 5 days at $30{ }^{\circ} \mathrm{C}$. Well containing lowest concentration that still showed inhibition zone around, it was seemed to be MIC. Meanwhile, minimum fungicidal concentration (MFC) was determined by cutting discs from inhibition zones with cork borer and re-inoculating on to a fresh Czapek's agar and highest dilution where there were no survivors was recorded as MFC. Antifungal antibiotics discs (Hi-media Laboratories Ltd.) including nystatin, ketoconazole, clotrimazole and itraconazole were aseptically placed over inoculated agar plates seeded with $0.2 \mathrm{ml}$ spores suspension $\left(10^{6}\right.$ spores/ $\left.\mathrm{ml}\right)$ as positive reference standards. Incubation conditions were running as mentioned in bioassay of AGE.

In vivo tests: Twelve rabbits with healthy eyes were assigned into two groups. Eyes of the first group (control) were topically treated once daily with $1 \mathrm{ml}$ sterile distilled water while, eyes of the second group (test) were topically treated with $1 \mathrm{ml}$ A. flavus $\mathrm{OC} 1$ conidial spore suspension containing $2 \times 10^{6}$ spores and examined daily for appearance of fungal infection and as soon as infection becomes apparent, treatment was carried out by topical application of $1 \mathrm{ml}$ of AGE. This amount of solution of $3.60 \mathrm{mg} / \mathrm{ml}$ concentration with $\mathrm{pH}=5.5$ was revealed to be the MIC. Application was carried out once daily. Rabbit's cornea was followed up at different stages till complete healing of mycotic infection that was confirmed by clinical examination and negative laboratory cultures for all treated corneal infection. 


\section{Fungal cyto-morphological study}

For evaluating cyto-morphological alterations induced by AGE in A. flavus OC1, a mycelium sample was taken from 10 days old culture grown in Czapek's broth containing AGE (2.88 $\mathrm{mg} / \mathrm{ml}$ ) and examined microscopically.

Light microscope (LM): Samples were fixed in lactophenol-cotton blue stain. Morphological changes were examined and photographed using a computerized LM (Motic images 2000, Micro- Optic. Industrial Group Co - Ltd, Japan).

\section{Transmission electron microscope (TEM)}

preparations: Samples for TEM were immersed in a primary fixative of $2.5 \%$ glutaraldehyde for $3 \mathrm{~h}$, buffered to $\mathrm{pH} 7.4$ with $0.2 \mathrm{M}$ phosphate buffer for $30 \mathrm{~min}$ and post fixed in $1 \%$ osmium tetraoxide for $2 \mathrm{~h}$, buffered again with phosphate buffer for $30 \mathrm{~min}$. All steps of fixation were carried out at $4^{\circ} \mathrm{C}$. Samples were then dehydrated in ethanol graded series (50 to $100 \%$ ), passed in 3 changes acetone: ethanol (1:2, 1: 1 and 2: 0) for $10 \mathrm{~min}$ each at room temperature and embedded in resin capsule. Capsules containing samples were sectioned with a diamond knife (Ultramicrotome RMC, USA) into ultrathin sections about $70 \mathrm{~nm}$ that were carried out on copper grids and contrasted with uranium acetate and lead citrate before examination in JEOL-1200 EX microscope.

\section{Effect of AGE on mycelial growth and aflatoxin B1} formation of A. flavus OC1

Growth conditions and treatment of A. flavus OC1 with different concentrations of AGE: This was carried out, as follows: a)- Contact method: Czapek's broth $(\mathrm{pH}=5.5)$ was prepared and sterilized in conical flasks of $250 \mathrm{ml}$ capacity, each containing $50 \mathrm{ml}$ medium. Different concentrations of AGE were added separately to broth to give the following concentrations; $0.0,0.18,0.36,0.72,1.44,2.16$ and 2.88 $\mathrm{mg} / \mathrm{ml}$. To each flask, $0.2 \mathrm{ml}$ of $A$. flavus conidial spore suspension $\left(10^{6}\right.$ spores/ $\left.\mathrm{ml}\right)$ from $168 \mathrm{~h}$ old culture was inoculated aseptically and incubated at $30^{\circ} \mathrm{C}$ for 10 days. Cultures were observed visually at the end of incubation period. b) - Fumigation method: Details of this method were running as contact method except mode of application of AGE where, desired concentration was aseptically absorbed on a circular cotton piece on top of flasks.

Determination of mycelial dry weights: At the end of incubation period, fungal cultures were filtered through preweighted Whatman no.1 filter papers, oven dried at $80{ }^{\circ} \mathrm{C}$ to a constant weight.

Extraction and determination of Aflatoxin B1 from $A$. flavus OC1 cultures: A known volume of culture filtrate was transferred to a separating funnel, extracted with equal volume of chloroform, shaked for about $30 \mathrm{~min}$, and allowed to stand for $30 \mathrm{~min}$. The chlororform layer was filtered over anhydrous sodium sulfate then evaporated under vacuum till dryness. The resultant dried crude extract was dissolved in methanol and undergone the necessary chromatographic analysis using pre coated thin layer chromatographic (TLC) plates with silica gel GF-254. The concentrated extracts and authentic aflatoxin B1 (Sigma CO.) were loaded on the chromatograms and developed in toluene: ethyl acetate: formic acid (6: 3: 1, v: v: v). Aflatoxin $\mathrm{B} 1$ bands $\left(\mathrm{R}_{\mathrm{f}}=0.47\right)$ give blue influorescence under short- and long-wave length (254 and $366 \mathrm{~nm}$ ) ultraviolet light using Min UVIS, DUOUV source for TLC. The fluorescent bands were eluted from the silica gel and rechromatographed with the same conditions for further purification. Fluorescent bands corresponding to the authentic aflatoxin B1 were again scrapped off and eluted with methanol. Aflatoxin B1 was then quantified by ultraviolet spectroscopic analyses performed with a Deuterium UV 21-D Milton Roy spectrophotometer. Aflatoxin B1 absorption was monitored at $363 \mathrm{~nm}$ and concentration was obtained after recording optical density against a standard curve (11).

\section{Statistical analyses}

All experiments were conducted in triplicates. Antifungal activity data from diffusion experiments were evaluated using analysis of variance (ANOVA) test followed by least significant difference (LSD) test. Data of the effect of AGE on the dry cell weights and aflatoxin B1 formation were analyzed 
by Student's $t$-test.

\section{RESULTS AND DISCUSSION}

Sensitivity of $A$. flavus strains to different concentrations of AGE compared to sensitivity to antibiotics

AGE showed a great potential for antifungal activity against A. flavus OC1 and OC10 (Table 1). Growth inhibition zones diameters of the first and the latter strain were $29.0 \mathrm{~mm}$ and $35.3 \mathrm{~mm}$, respectively, upon applying of AGE at 36.0 $\mathrm{mg} / \mathrm{ml}$. AGE exhibited the same MIC and MFC value of 3.60 $\mathrm{mg} / \mathrm{ml}$ against the two strains. This value is within the range of values recorded for antifungal activity of garlic extract against fungal radial colony growth (22) but is relatively lower than value obtained by Pundir et al. (21). Significant difference (P $<0.05$ ) was obtained in values of inhibition zone diameters of the two strains by antibiotics tested (Table 2). A. flavus OC10 was highly sensitive to higher concentrations of AGE (28.8 and $36.0 \mathrm{mg} / \mathrm{ml}$ ), sometimes even more sensitive than antifungal antibiotics. Regarding to A. flavus OC1, similar inhibitory effects were produced upon applying $36.0 \mathrm{mg} / \mathrm{ml}$ of AGE and tested antibiotics. Antimicrobial potency of garlic has been attributed to different concentrations of active biosubstances coupled with sulfhydryl agents (18). Meanwhile, allicin and other disulfides have found at different concentrations determined by age and method of extract preparation (5).

Table 1. Sensitivity of A. flavus $\mathrm{OC} 1$ and A. flavus OC10 to different concentrations of AGE

\begin{tabular}{ccc}
\hline \multirow{2}{*}{ Concentration of AGE $(\mathbf{m g} / \mathbf{m l})$} & \multicolumn{2}{c}{ Zone of inhibition (mm) } \\
\cline { 2 - 3 } & A. flavus OC1 & A. flavus OC10 \\
\hline 2.88 & - & - \\
3.60 & $20.0^{\mathrm{d}}$ & $20.3^{\mathrm{e}}$ \\
7.20 & $21.3^{\mathrm{cd}}$ & $23.0^{\mathrm{d}}$ \\
14.4 & $23.7^{\mathrm{c}}$ & $24.3^{\mathrm{d}}$ \\
21.6 & $26.0^{\mathrm{b}}$ & $29.7^{\mathrm{c}}$ \\
28.8 & $27.0^{\mathrm{b}}$ & $33.3^{\mathrm{b}}$ \\
36.0 & $29.0^{\mathrm{a}}$ & $35.3^{\mathrm{a}}$ \\
\hline a-e Means with different superscripts in the same column are considered statistically different (LSD test, P $<0.05)$.
\end{tabular}

Table 2. Sensitivity of A. flavus $\mathrm{OC} 1$ and A. flavus $\mathrm{OC} 10$ to known antifungal antibiotics

\begin{tabular}{ccc}
\hline \multirow{2}{*}{ Antibiotics } & \multicolumn{2}{c}{ Zone of inhibition (mm) } \\
\cline { 2 - 3 } & A. flavus OC1 & A. flavus OC10 \\
\hline Nystatin $(100 \mathrm{U})$ & $29.0^{\mathrm{a}}$ & $32.0^{\mathrm{a}}$ \\
Ketoconazole $(10 \mathrm{mcg})$ & $29.6^{\mathrm{a}}$ & $29.6^{\mathrm{b}}$ \\
Clotrimazole $(10 \mathrm{mcg})$ & $26.6^{\mathrm{b}}$ & $27.0^{\mathrm{c}}$ \\
Itraconazole $(10 \mathrm{mcg})$ & $17.6^{\mathrm{c}}$ & $21.6^{\mathrm{d}}$ \\
\hline a-d & Means with different superscripts in the same column are considered statistically different (LSD test, P $<0.05)$.
\end{tabular}

Treatment of rabbit's fungal keratitis caused by A. flavus OC1

Infection of rabbits' eyes with A. flavus conidial spore suspension showed that early fungal keratitis begins with inflammation or redness of eyelid (conjunctiva) (Fig. 1a) after 5-8 days of infection. Inflammation extends to portion of eye ball that comes into contact with conjunctiva after 12 days
(Fig. 1b \& c). After 15 days, it may appear as indolent and dry, with a leathery, tough, raised surface (Figure 1d). Some feathery borders may be noted at this stage of infection (Fig. 1e). After 16 days, the eye inside is not visible (Fig. 1f). These clinical symptoms are consistent with reported studies $(2,3)$.

In vivo application of AGE showed that low concentration (MIC $=3.60 \mathrm{mg} / \mathrm{ml}$ ) has succeeded to cure severe A. flavus 
keratitis in a time course less than 10 days without any observable side effects; there was no tear secretion, no hypersensitivity reactions, or no any inflammation. Fig. 2a shows a gradual decrease in inflammation and redness of conjunctiva and portion of eye ball within a period of 5- 8 days. Fig. 2 b, c show a complete healing rate of mycotic keratitis within a period of 8-10 days. Treatment of fungal keratitis may pose difficult problem because most topical antifungal medications are expensive and not usually available in developing countries. Polyenes, azoles and pyrimidines are approved for keratomycosis (8). Antiseptics such as chlorohexidine $(0.2 \%)$ and povidone iodine $(5 \%)$ have also been advocates as alternatives but are not as effective (19). Garlic was used in topical treatment of the fungal infection by tinea pedis, tinea cruris and tinea corporis $(15,16)$.
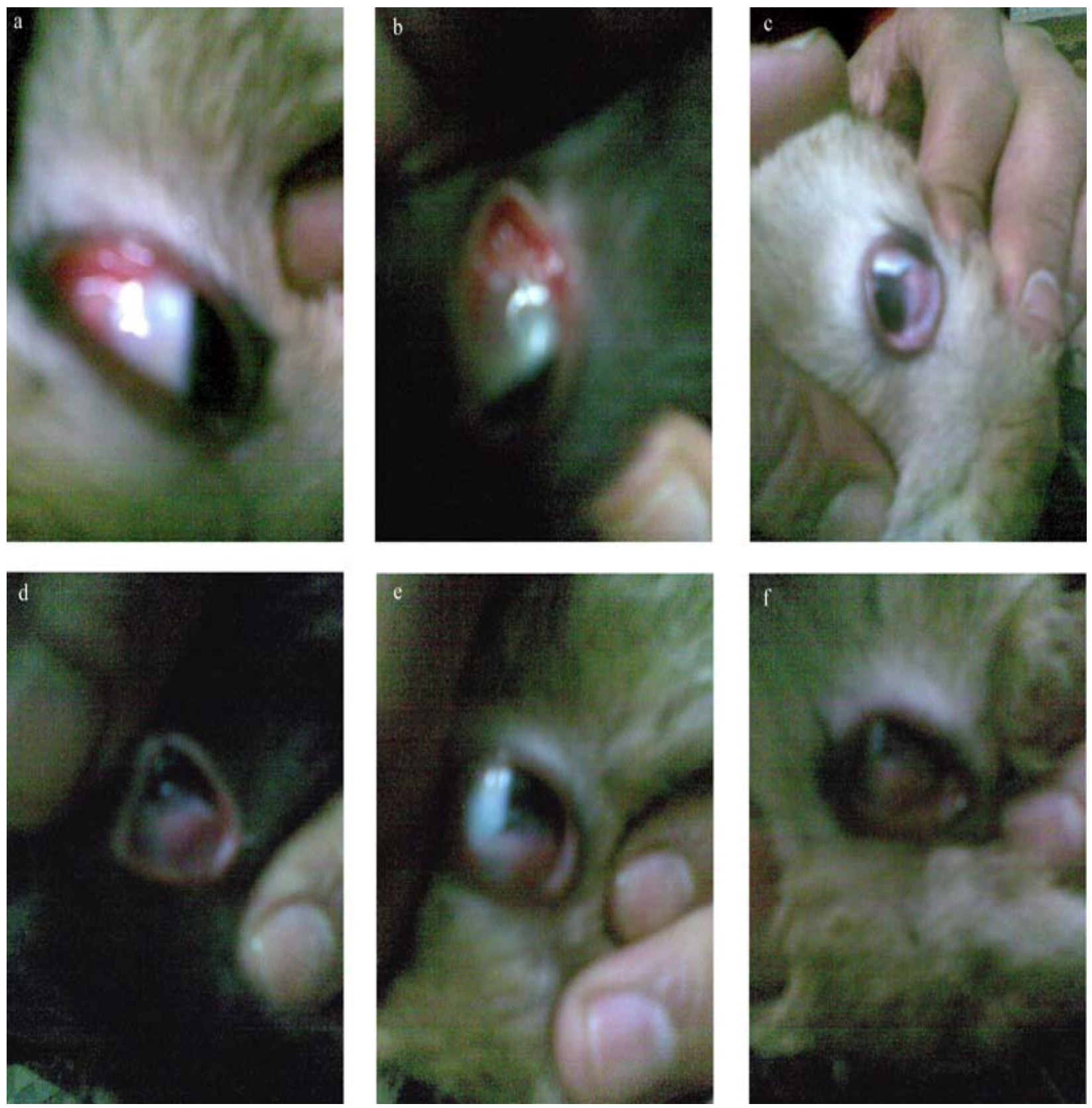

Figure 1. In vivo infection stages of rabbit's cornea with A. flavus OC1 conidial spore suspension showing fungal keratitis. (a): After 7days of infection; (b), (c): After 12-days of infection; (d), (e): After 15-days of infection and (f): After 16-days of infection. 

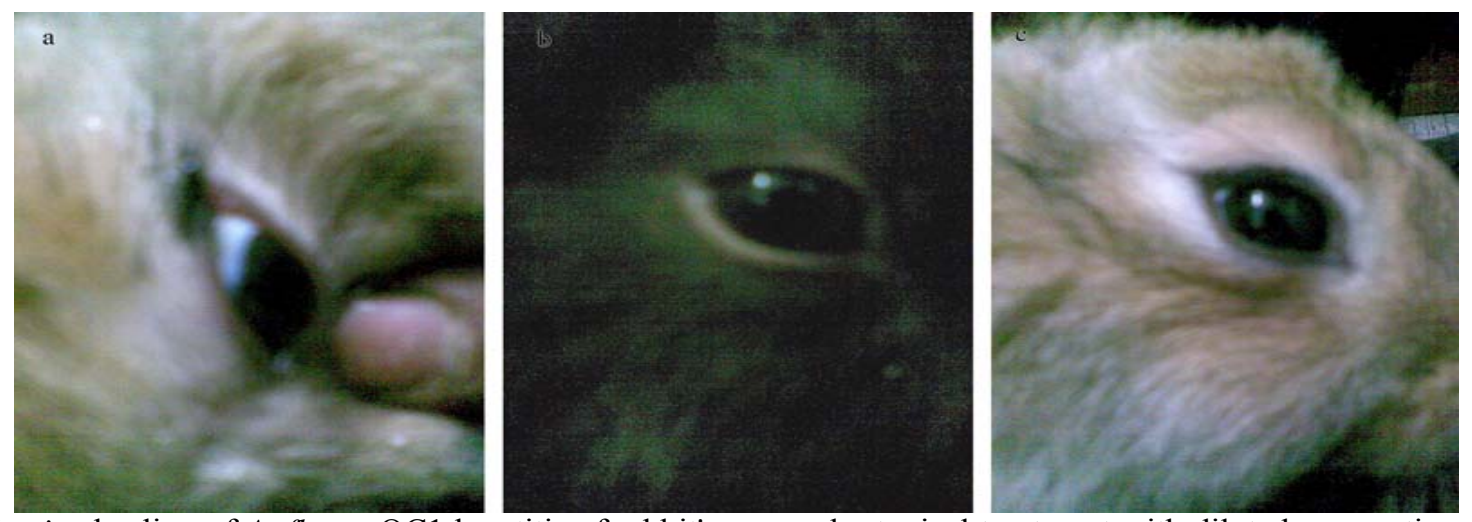

Figure 2. In vivo healing of A. flavus OC1 keratitis of rabbit's cornea by topical treatment with diluted preparation of AGE (3.60 $\mathrm{mg} / \mathrm{ml}$ ). (a): A healing stage after 6-days; (b): A healing stage after 9-days; (c): A healing stage after 10-days.

\section{LM examination}

LM examination of $A$. flavus OC1 control culture showed a regular cell structure of mycelium with homogenous cytoplasm, clearly visible strigmata bearing conidia and profuse conidiation on a large and radiated conidial head (Fig. 3a). Examination of AGE-treated A. flavus growth revealed morphological changes including decreased conidiation (lack of sporulation), visible loss of cytoplasm content, loss of pigmentation and reduction in conidial heads, with distorted presence of conidiophores (Fig. 3b). Moreover, hyphae appeared thinner than those of controls. A reported study (4) showed that AGE causes collapse of hyphae of Rhizoctonia solani and Colletotrichum lindemuthianum and for Fusarium solani hyphae appeared thinner than in controls. Garlic extract was found to reduce germination of conidiophores and oospores of Hyaloperonospora parasitica (5).

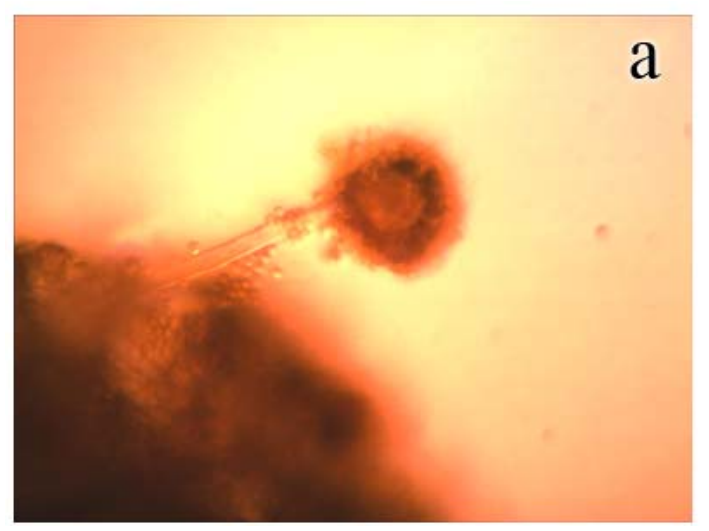

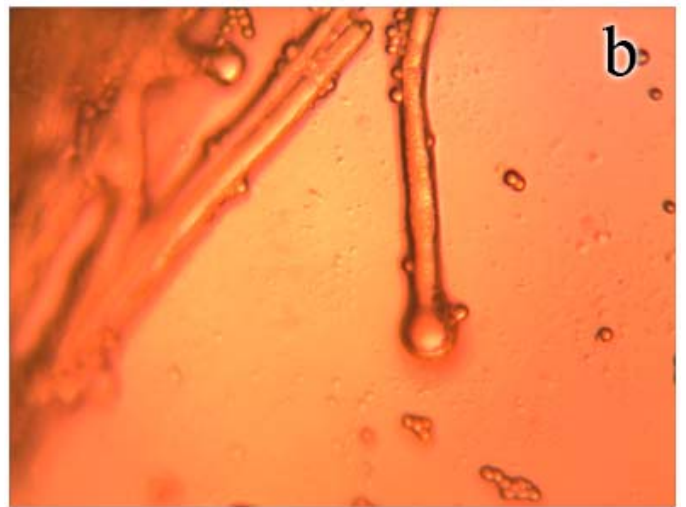

Figure 3. Light micrographs (X 400) of A. flavus OC1 control (without AGE treatment) and sample (treated with $2.88 \mathrm{mg} / \mathrm{ml}$ of AGE). (a): Control conidial head of A. flavus, large and radiated, development of vesicle on conidiophore and conidia are clearly visible; (b): Sample of conidial head of A. flavus showing morphological aberrations induced by AGE. A decrease in conidiation is clearly visible.

\section{TEM examination}

TEM examinations of control cells of A. flavus OC1 showed that cell wall and plasma membrane were smooth and uniform and thoroughly surrounded by intact fibrillar layer and all organelles are suspended in highly dense cytoplasm have normal appearance (Fig. 4a). TEM images of AGE-treated fungal cells of the same age (Fig. 4b, c) showed singular accumulation of osmophil bodies immediately under plasma membrane which became rough and irregular with continuous 
folding in cytoplasm and detachment of fibrillar layer was also observed. Disappearance of surface ornaments due to presence of massive vacuolation of cytoplasm and spaces filled with amorphous material. Hyphal tips treated with AGE, besides the increase in spaces filled with amorphous material, showed a strong thickening of cytoplasmic membrane that was partially detached from cell wall (Fig. 4 e), whereas the control revealed highly dense cytoplasm and was enveloped with tightly attached cell wall and cytoplasmic membrane (Fig. 4 d). Some hyphal tips were found disintegrated (Fig. 4 f). These modifications series are similar to those observed in other fungal species during treatments with garlic extracts $(4,13,27)$.
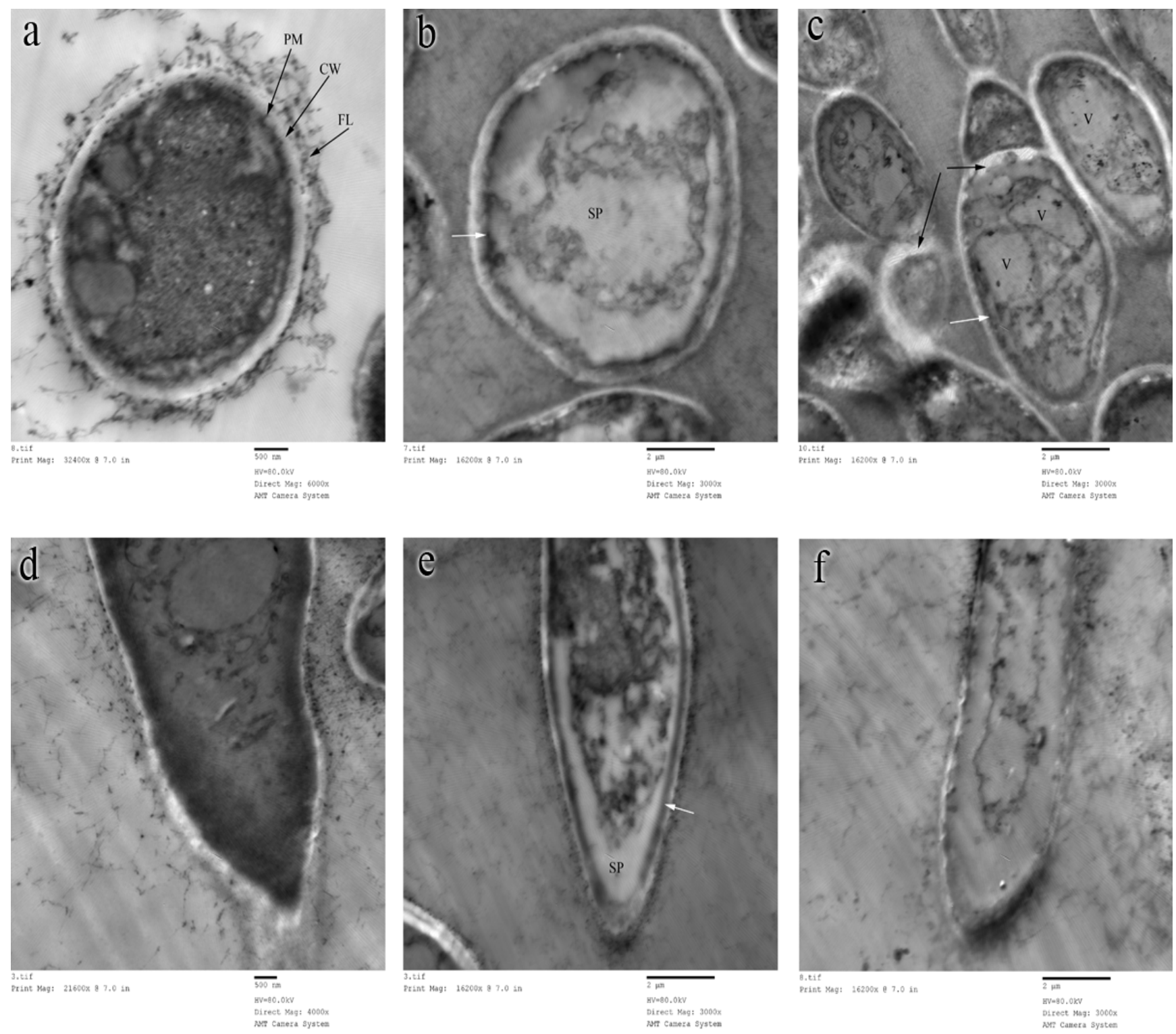

Figure 4. TEM of 10-days old A. flavus OC1 control (without AGE treatment) and sample (treated with $2.88 \mathrm{mg} / \mathrm{ml}$ of AGE). (a): Control cell; (b), (c): Sample cells, the white arrows show accumulation of osmophil material, the black arrows show detachment of septum of plasma membrane; (d): Control tip of hypha, (e): Sample tip of hypha, the white arrow shows detachment of plasma membrane from cell wall; (f): Sample tip of collapsed hypha. FL, fibrillar layer; CW, cell wall; PM, plasma membrane; SP, spaces filled with amorphous material and $\mathrm{V}$, vacuole. 
Effect of different concentrations of AGE via contact and vapor phase on mycelial and sporulative growth and aflatoxin B1 formation of A. flavus OC1

Using contact method, aflatoxin B1 production was completely inhibited at $0.72 \mathrm{mg} / \mathrm{ml}$. However, a significant drastic reduction in aflatoxin B1 production from $299.7 \mathrm{ppb}$ at $0.18 \mathrm{mg} / \mathrm{ml}$ of AGE to $144.6 \mathrm{ppb}$ at $2.88 \mathrm{mg} / \mathrm{ml}$ was obtained by fumigation method (Table 3 ). Garlic was reported to have antifungal properties and inhibit formation of aflatoxins (9) and penicillic acid (10). At $2.88 \mathrm{mg} / \mathrm{ml}$, growth was significantly reduced by $75.5 \%$ via contact method and $36.4 \%$ via fumigation method, compared with growth at respective control cultures. Meanwhile, growth was slightly stimulated by $3.80 \%$ when broth was supplemented with AGE at the lower concentration, $0.18 \mathrm{mg} / \mathrm{ml}$ (via contact method). However, it was reduced by $4.35 \%$ when medium was fumigated with AGE at the same concentration (via vapor method) compared with control culture. This was consistent with reported findings $(9,10)$, where apparent stimulation of mycelial weights production at lower garlic concentrations was due to presence of small amounts of nutrients such as minerals and vitamins in the added garlic. However, remarkable reduction in growth at $0.36 \mathrm{mg} / \mathrm{ml}$ may be due to presence of higher concentration of allicin and sulfides in the extract which were sufficient to inhibit or reduce mycelial growth. Inhibition of Micrococcus luteus in seeded agar via vapor phase of garlic extract was reported (5). Regarding to effect of AGE on spore production (Table 3), contact phase was more effective in inhibiting sporulation than vapor phase. Via vapor phase of all concentrations, sporulation was intense as well as control. Via contact phase, sporulation was intense at lower concentrations $(0.18$ and $0.36 \mathrm{mg} / \mathrm{ml})$, became slight to very slight at concentrations $(0.72$ to $2.16 \mathrm{mg} / \mathrm{ml})$ and completely inhibited at higher concentration $(2.88 \mathrm{mg} / \mathrm{ml})$. Similarly, garlic was found to inhibit sporulation of $A$. parasiticus (9) and $P$. hirsutum (10). Via contact phase, reduction of sporulation was correlated with reduction in aflatoxin $\mathrm{B} 1$ production. This was consistent with findings of Reib (23).

Table 3. Dry cell weights and production of spores and aflatoxin B1 of A. flavus OC1 in Czapek's medium supplemented with different concentrations of AGE via the contact and vapor phase, after 10 days of incubation

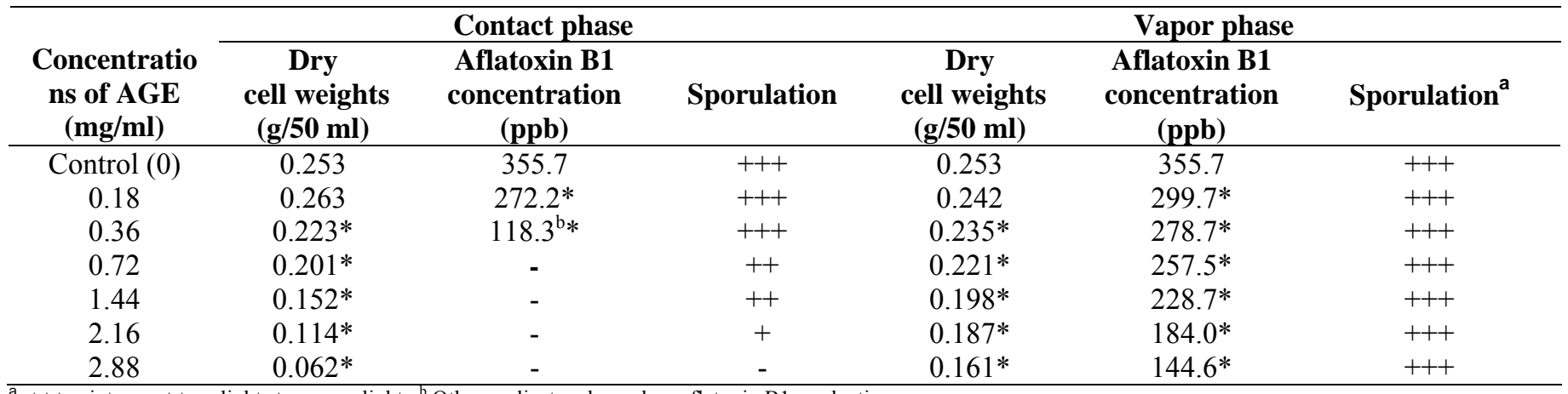

$\mathrm{a}+++=$ intense,$++=$ slight,$+=$ very slight. ${ }^{b}$ Other replicates showed no aflatoxin B1 production

*Significantly different from control $(\mathrm{P}<0.01$, Student's $t$-test $)$

\section{CONCLUSION}

AGE may offer a natural source of antifungal agent against A. flavus. Its medicinal value is comparable to the present day antibiotics. AGE has succeeded topically to cure the severe A. flavus keratitis of rabbits in a time course less than 10 days without any observable effects. It induced deleterious cyto-morphological alterations of A. flavus. AGE in contact phase was more effective in inhibiting growth, spores and aflatoxin $\mathrm{B} 1$ production of $A$. flavus than in vapor phase. Therefore, AGE appears to have clinical and public health importance. A histopathological study will be carried out to 
approve safety of AGE to be applied topically on eyes.

\section{ACKNOWLEDGEMENTS}

We thank the technicians of the Central Laboratory of Electron Microscope, Faculty of Science, Ain-Shams University, Egypt for performance of the processing steps of TEM.

\section{REFERENCES}

1. Abu EL- Rob, S.M. (1991). Medicine and pharmacy during ages. AL Ahleea Press, Amman, Jordan, pp. 28- 29.

2. Alfonso, E.C.; Rosa Jr. R.H.; Miller, D. (1997). Fungal keratitis, in: Krachmer, J.H.; Mannis, M.J., Holland EJ (Eds), Cornea, Vol II. Cornea and External Disease: Clinical Diagnosis and Management. St. Louis, MO, Mosby-Year Book, pp 1253-1265.

3. Bharathi, M.J.; Ramakrishnan, R.; Vasu, S.; Meenakshi, R.; Palaniappan, R. (2003). Epidemiological characteristics and laboratory diagnosis of fungal keratitis: a three-year study. Indian J. Ophthalmol. 51, 315- 321 .

4. Bianchi, A.; Zambonelli, A.; Zechini D'Aulerio, A.; Bellesia, F. (1997). Ultrastructural studies of the effects of Allium sativum on phytopathogenic fungi in vitro. Plant Dis. 81, 1241-1246.

5. Curtis, H.; Noll, U.; Störmann, J.; Slusarenko, A.J. (2004). Broadspectrum activity of the volatile phytoanticipin allicin in extracts of garlic (Allium sativum L.) against plant pathogenic bacteria, fungi and Oomycetes. Physiol. Molecul. Plant Pathol. 65, 79- 89.

6. Eaton, D.L.; Groopman, J.D. (1994). The toxicology of aflatoxins: human health, veterinary and agricultural significance. Academic Press, San Diego, CA.

7. Fenwick, G.R.; Hanley, A.B. (1985). The genus Allium- Part 3. Medicinal effects. CRC Crit. Rev. Food Sci. Nutr. 23, 1- 73.

8. Ford, M.M. (2004). Antifungals and their use in veterinary ophthalmology. Vet. Clin. Small Anim. 34, 669- 691.

9. Graham, H.D.; Graham, E.J.F. (1987). Inhibition of Aspergillus parasiticus growth and toxin production by garlic. J. Food Safety. 8, $101-108$.

10. Ismaiel, A.A. (2009). Inhibitory effect of Egyptian Garlic extract on penicillic acid production. Egypt. J. Microbiol. 44, 1- 14.

11. Ismaiel, A.A.; Ghaly, M.F.; El-Naggar, A.K. (2011). Milk kefir: Ultrastructure, antimicrobial activity, and efficacy on aflatoxin B1 production by Aspergillus flavus. Curr. Microbiol. 62, 1602-1609.

12. Khairallah, S.H.; Byrne, K.A.; Tabbara, K.F. (1992). Fungal keratitis in
Saudi Arabia. Doc. Ophthalmol. 79, 269-276.

13. Khan, M.A.; Zhihui, C.; Xuemei, X.; Khan, A.R.; Ahmed, S.S. (2011). Ultrastructural studies of the inhibition effect against Phytophthora capsici of root exudates collected from two garlic cultivars along with their qualitative analysis. Crop Protect. 30, 1149-1155.

14. Krishnan, S.; Manavathu, E.K.; Chandrasekar, P.H. (2009). Aspergillus flavus: an emerging non-fumigatus Aspergillus species of significance. Mycoses 52, 206- 222.

15. Ledezma, E.; López, J.C.; Marin, P.; Romero, H. (1999). Ajoene in the topical short-term treatment of tinea cruris and tinea corporis in humans: randomized comparative study with terbinafine. Arzneim-Forsch/Drug Res. 49, 544-547.

16. Ledezma, E.; Marcano, K.; Jorquera, A. (2000). Efficacy of ajoene in the treatment of tinea pedis: a double-blind and comparative study with terbinafine. J. Am. Acad. Dermatol. 43, 829- 832.

17. Moubasher, A.H. (1993). Soil Fungi in Qatar and Other Arab Countries. The Centre for Scientific and Applied Research, Doha, Qatar.

18. O'Gara, E.A.; Hill, D.J.; Maslin, D.J. (2000). Activities of garlic oil, garlic powder and their diallyl constituents against Helicobacter pylori. Appl. Environ. Microbiol. 66, 2269- 2273.

19. Panda, A.; Ahuja, R.; Biswas, N.R.; Satpathy, G.; Khokhar, S. (2003). Role of $0.02 \%$ polyhexamethylene biguanide and $1 \%$ povidone iodine in experimental Aspergillus keratitis. Cornea. 22, 138- 141.

20. Park, D.L. (1993). Controlling aflatoxin in food and feed. Food Technol. 47, 92-96.

21. Pundir, R.K.; Jain, P.; Sharma, C. (2010). Antimicrobial activity of ethanolic extracts of Syzygium aromaticum and Allium sativum against food associated bacteria and fungi. Ethnobotanical Leaflets. 14, 344360 .

22. Rees, L.P.; Minney, S.F.; Plummer, N.T.; Slater, J.H.; Skyrme, D.A. (1993). A quantitative assessment of the antimicrobial activity of garlic (Allium sativum). World J. Microbiol. Biotechnol. 9, 303- 307.

23. Reib, J. (1982). Development of Aspergillus parasitics and formation of aflatoxin B1 under the influence of conidiogenesis affecting compounds. Arch. Microbiol. 133, 236- 238.

24. Reuter, H.D.; Koch, H.P.; Lawson, L.D. (1996). Therapeutic effects and applications of garlic and its preparations, in: Koch, H.P.; Lawson, L.D. (Eds.), Garlic. The Science and Therapeutic Application of Allium sativum L. and Related species. Second Ed.,Williams and Wilkins, Baltimore, pp. 135- 212.

25. Richard J.L.; Payne, G.A.; Desjardin, A.E.; Maragos, C.; Norred, W.P.; Pestka, J.J.; Phillips, T.D.; Van Egmond, H.P.; Vardon, P.J.; Whitaker, T.B.; Wood, G. (2003). Mycotoxins, risks in plant, animal and human systems. CAST Task Force Report 139. Council for Agricultural Science and Technology. Ames, Iowa, USA, pp. 101- 103.

26. Sarrell, E.M.; Mandelberg, A.; Cohen, H.A. (2001). Efficacy of naturopathic extracts in the management of ear pain associated with 
acute otitis media. Arch. Pediatr. Adolesc. Med. 155, 796-799.

27. Yoshida, A.S.; Kasuga, S.; Hayashi, N.; Ushiroguchi, T.; Matsuura, H.;
Nakagawa, S. (1987). Antifungal activity of ajoene derived from garlic. Appl. Environ. Microbiol. 53; 615-617. 